\title{
GRADE AS THE MOTIVATIONAL FACTOR IN LEARNING MATHEMATICS
}

\section{Sead Rešić ${ }^{1}$}

Amna Bajramović Anela Hrnjičić

\author{
Original scientific paper
}

DOI:10.21554/hrr.091702

Department of Mathematics, Faculty of Sciences, University of Tuzla, Bosnia and Herzegovina Elementary school "Travnik", Travnik, and „, Safvet-beg Bašagić", Novi Travnik, Bosnia and Herzegovina Mixed secondary technical school Travnik, Travnik, Bosnia and Herzegovina

Received: 11.05.2017

Accepted: 10.08.2017

\begin{abstract}
In this research the motivation for learning mathematics was tested, as well as the effect of grades on the motivation of primary school level students. On a sample of $N=100$ participants, primary school students, we conducted a survey, the results of which show that the participants are more motivated with extrinsic factors, then intrinsic factors for learning mathematics. Grades are the main factor that has the most influence on the motivation level of students for learning mathematics, because students need good grades for their further education. The results also show that punishment and rewards from parents for bad and good grades has no effect on the motivation level of students.
\end{abstract}

Keywords: grade, motivation, learning, mathematics

\section{INTRODUCTION}

Fundamental task in the teaching of mathematics is for students to adopt mathematical knowledge which is needed for making justified decisions in everyday life.Curriculumof mathematics resembles the need to prepare students for critical thinking and changing of the society. Mathematics is the way to understand the world. As a school subject mathematics needs to secure solid foundation for learning other subjects in every other educational area:technical and technological, social and humanistic, natural sciences, linguistics and communications, art, and even physical health education and in the practical work and design. It is also foundation for further education and lifelong learning.

The educational role of mathematics means that it has a share in the training and formation of the personal- ity of students. To educate students in general, even in mathematics, it means to develop these things in them (Rešić, 2013):

- Intellectual area - The intellectual training of students includes the development of mental abilities, among which most important are attention, observation, performance of thinking operations, logical reasoning, the possession of intuition, imagination and memory.

- Morale area - teaching mathematics is educational act that develops positive characteristics and will of students. Dealing with mathematics develops in students' perseverance, patience, systematism, initiative, self-control, meticulousness, discipline, and these are all the moral virtues that have personalities with strong character.

\footnotetext{
${ }^{1}$ Correspodence to:

Šabana Zahirovića 10, Tuzla, B\&H

Phone: +38761 101230

E-mail: sresic@hotmail.com
}

Sead Rešić, Department of Mathematics, Faculty of Sciences, University of Tuzla 
Aesthetically area - Math can provide lasting intellectual pleasure, colored with aesthetic and emotional tones, so that at the same time it is deepening knowledge and refining taste. Math among students develops a sense of symmetry, harmony, precision, clarity, and other and all of these are elements of beauty.

- Work-technical field - Working-technical training of students through teaching mathematics is multiple: development of a positive attitude towards work, forming of certain abilities, skills and habits that are necessary for practical activity.

Preparedness of teachers is a form of respect for students because only prepared teacher is ready to answer questions. However, it is necessary to be ready and to adjustments in the course of time of the class depending on the reactions of students. Questions should be responded with respect, if you require a long answer, give a brief one and encourage students to ask you after the class if possible. It is very important that your reaction is commendable (e.g. 'This is an important idea'), but never offensive.

Respect is also seen in specifying the rules - which you will also comply to (e.g. about grades, assignments...) encourage activity and communication (avoiding unidirectionality). Accent in teaching is placed on the understanding of mathematics and its application in the real world. Start of the class is particularly important. Preparedness protects against the unpleasant / serious questions as prepared teacher can concentrate on the very activity of teaching. However: no need to overdo it and lose all spontaneity. The aim is to ensure the preparation of a mix-up in the middle of the class, and not to prevent thinking about what is taught. Preparation gives sufficient assurance that it can be responded to the casual questions, to make certain adjustments during the lectures and to submit certain digressions (and lecturer to still be able to return to the main topic). It is recommended that after every class you think of your lecture - what was good and what is not?

In education, following teaching and motivational techniques can be used: crossword puzzles, networks, boo games, associations, quizzes and mental maps. Quizzes can be very different. All students can compete, groups or specific students. Quizzes can be designed as a current television quizzes. Along with them are often used puzzles, rebuses, game of gallows, short sound recordings, short videos, cartoons, drawings, mime, pantomime, clothing, objects, models, balls, dolls, collage, different games, drawing, funny short stories, anecdotes, quotations, metaphors and so on.In schoolsare usually used motivational techniques of writing down thoughts or brainwriting and storm of ideas or brainstorming.

The purpose of motivational techniques in the classroom is quick and efficient learning of new words, years, names and events. These motivational techniques relate to course content and motivate students to learn new teaching facilities.

Teachers can increase or decrease the complexity of the content with the help of teaching motivational techniques (higher number of new concepts and terms, etc.), and can used them for any educational content in teaching.

Special motivational techniques however are designed for relaxation and a short break for students. These techniques are especially relaxing with music (with breathing exercises), with movement (eg, lifting a hand, getting up, changing the seating arrangements, etc.), or special techniques of meditation or relaxation (with the emphasis on the power of words). Motivational relaxation techniques can be used at the beginning of the class or before the execution of demanding tasks.

Music can help create a special mood for the pupils. It is most commonly used as sound background before the start of the class and during the breaks. It can also be used as an aid or supplement to the exercises of relaxation, especially at the beginning of the class or before the evaluation. Music can also be used as a background while reading or listening to the source texts, or as background when processing a new teaching material (Dhority, 1992, p. 111). Teachers can choose a special music for the repetition of teaching material, and as a motivation for new teaching material (classical, folk, popular music ...), and a special music during the processing of the teaching material (for example, the classic music of the 19th century in order to attract the attention of the students or the Baroque music for comprehensive exposition of the teaching material), while training and during active participation of the pupils a special music can be used in combination with reading text or answering the questions (individually, in pairs or all students). In the teaching folk dances and singing of folk songs, or similar can be used.

A special motivational technique that involves movement can be used when applying the method of conversation or when determining and repetition of material. For example, students can answer questions by raising the left arm (the exact statement) or raising your right hand (incorrect assertion), all students can rise up, and then, in the case of incorrect claims sit etc. 
In addition,clapping of hands can be used. In teaching students share teaching/worksheets for the classroom, help teacher prepare teaching aids, and the like. Also, the game in which the teacher throws a smaller ball and sets different questions or student throws the ball and examines other students can be used. Throwing and catching a ball should affect the faster reactions and responses of students. Special technique of relaxation and concentration is carried out using the positive suggestions that can encourage, or influence the positive mood, thoughts, and feelings. With this technique students and teachers become aware of the moment and so enter into the teaching process.

Special relaxation techniqueis also a visualization, which allows students to easily and clearly present desired goals.

Barica Marentič Požarnik specifies the following options:

- Suitable degree of news, surprises, and unexpected and inconsistent analytic data,

- Periodically turn to the methods that encourage personal involvement of students,

- Simulations, role-plays,

- Organizing knowledge tests in the form of puzzles and quizzes,

- Enable a choice of themes and ways of how to perform certain tasks (pupils choose their literary works that will read and report or themes that they will explore) and elective courses can help in defining and extending student's interests;

- Interest and internal motivation is generally stronger withopportunityfor students to ask about what is not clear to them, to speak about their experiences and ideas and to express their opinions, even when they differ from the teacher's, which is enabled by open, democratic relations (Požarnik, 2000, p. 191).

Teachers can increase the motivation for a school or homework with authentic tasks (visual or in writinggraphics), work in groups, professional trips, working on various projects and research work and alternative assessment (collegial, self-evaluation) and in other ways. Teachers can use a variety of teaching strategies, methods and procedures that stimulate the interest of students and operate motivationally on them, for example, an image or oral demonstration, the use of a different image or the written materials, use of the Internet or $\mathrm{CD}$ etc.

With the method of exposure teachers can use special techniques such as relaxation techniques and visualization, metaphorical storytelling, global rollout of teaching materials, choice of words, variations of voice, music and the like.

Ways to encourage motivation for learning are often presented in the form of advice and basic rules for teachers.

The first rule applies to meeting basic requirements: provide an organized classroom environment. The teacher should behte one that supports, sets the tasks that are challenging but not too difficult. Make tasks that are worth solving.

The second rule is that the students' need to build selfconfidence and positive expectations: It should begin work on the student's level. May the learning objectives be clear, specific and achievable, emphasize comparing students' results, rather than competition.

The third rule is that students need demonstration of the values of learning: It is important to connect the teaching task with the needs of students, working activities that fit the interests of students, to stimulate curiosity. Make assignments entertaining for the students. New knowledge can be used, but also and what is already known, explain the connection between the current learning and later life.

The fourth rule is that teachers need to help students to stay focused on the task: Regularly enable students to produce works. It is necessary to avoid stressing the score and lower the risk of the task, but at the same time not to make the task too simplistic. It is necessary to model the motivation for learning and teach the teaching tactics to the students (Woolfolk, 2002, p. 373).

One of the rules of motivation is that it is necessary to make the most out of the introductory section at the beginning of each class. This part should be focused on the motivation for learning and work. Therefore, teachers using different motivational techniques should particularly pay attention to just the first few minutes of the class. The initial students' motivation, teachers can increase with the positive response to the following questions concerning the success, purpose, joy, encouragement and objective:

Success: Is it anticipated work at the appropriate level for students? The event takes place in the appropriate pace? Does every student do what suits his abilities, previous knowledge and experience? If the student's work is not at the required level, is it required of him to work until he succeeds?

Purpose: Do students understand personal advantage they will gain by learning what you teach? Do students value the importance of what they learn for work in life? Do you teach actively your subject and themes? 
Joy: Are your classes different? Do they include substantial activity from students? Are the activities that you use entertaining for the students, for example discussions, group work, games, competitions, criticism, etc.? Do you recognize the importance and the interest of the students?

Do pupils have the possibility to show creativity or expression, for example, in problem teaching or planned activities? Do you teach you with enthusiasm? Do you have a good relationship with the students?

Incentives: Do you often encourage your students, for example, with grades, comments, compliments, etc.? Are incentives and recognitions for success given in a timely manner, after the student has finished his work?

Objective: Are the goals worth it for your students to reach them? Do you check often and plan deadlines for submission of student's work? Do you set personal goals for students, and praise them as is appropriate? Do you encourage students to take responsibility for their own learning? Do you drive most talented students to determine their educational needs and set their own learning objectives and evaluate their learning and change it in accordance with the results?

Teachers should not ask simple questions, such as.: 'How to motivate students?', but rather the question: 'How to increase students' motivation?'

'Optimistic messages should be an integral part of the class. One of them could be: 'I know that today's work is a difficult challenge, but I know that we can all overcome it. Let's give our best! I have prepared some exercises that you may find tiresome, but you will eventually be delighted by what you have achieved.' Even for the inappropriate behaviour in the classroom teacher can use different motivational strategies - e.g. he may use a traffic light, or red, green and orange card, and in such way that he puts a green card or paper on the board when it is allowed for students to talk among themselves.

When a teacher puts orange card, it means that silence is expected within one minute, but if you put red card, this, of course, means that the class should be in complete silence (Ginnis, 2004, p. 221).

The teacher should offer students a variety of areas, tasks and activities for the election; he should include divergent questions and tasks; should introduce new elements, diversity and surprises; should constantly give specific feedback on success; should include elements of imagination and play; express positive ex- pectations for students; should introduce its own projects or projects in groups, learning in nature and so on. (Požarnik, 2000, p. 193).

The motivation for learning means directing energy to the achievement of the learning objectives. It is possible to use a variety of motivational techniques in this process. In any subject it is required that the student discovers and formulates for himself (Rakic, 1977, p. 105).

For motivation of students perseverance is important, and duration. The longer it lasts, the greater is the chance of success and completion of assigned tasks. Learning objectives which present the achievements that students should achieve are also important.

The stated goals improve the performance, because they focus attention on the task, include effort, increase persistence and enhance the development of new strategies for reaching goals. Reaching the educational objectives is influenced by the students' acceptance of the goals envisaged by the teacher; if students accept, these goals then encourage and motivate.

Motivational techniques in teaching refer to the knowledge of students and the new teaching material; they impact on the emotional engagement of students, and also to their interest and wishes. Motivational techniques can be classic, innovative, planned, spontaneous, short term, long term, opening, closing or inter-motivation. Due to the senses of students, they can be visual (sight), auditory (hearing), kinetic (movement), olfactory (smell) and gustatory (taste).

\section{RESEARCH}

A large number of students in primary schools have developed a negative attitudes, anxiety and resistance towards mathematics and they learn mathematics solely for the grades. The importance of knowledge of the basic elements of the subject of mathematics is crucial for the further education of students, but also for functioning in everyday life. It is therefore important to examine the factors that motivate students to learn and master the knowledge of mathematics. Grade in mathematics has a big impact on students for their motivation towards the subject. According to that, basic problem of this research will be to examine how evaluation of students in mathematics has an impact on their motivation and developing their attitudes towards mathematics. 


\section{Methods and techniques of research}

The paper the following research methods will be used:

- Survey research method.

- The method of theoretical analysis.

For the processing of data following statistical methods will be used:

- Descriptive statistical methods.

- Correlation.

$\cdot \mathrm{t}$ - Test.

\section{Model of research}

In the study participated a total of $\mathrm{N}=100$ subjects, students of elementary school 'Safet Basagic' Novi Travnik. Of these 25 students were of sixth grade, 25 students of seventh, 25 of eighth and 25 of the ninth grade. Students filled conveniently made questionnaire for this study which we in addition to basic socio-demographic data of students,collected data and information relating to their motivation and factors that motivate them in terms of learning mathematics. Participation in the study was voluntary and parents of children were notified prior to the survey on the participation of their children in the mentioned study.

\section{The organization and process of research}

The survey was conducted during the school year $2015 / 2016$. Testing participants lasted for four days. Each class (sixth, seventh, eighth and ninth) was tested one day. The study was conducted in the framework of regular teaching formal classes and in classes of mathematics. Before conducting research students the purpose and intent of research was explained to them, and it was made clear that their answers are completely anonymous and will be analyzed solely on group, and not at the individual level. Students were asked to provide open and honest answers and that in case of ambiguity they contact the teacher. Participation in research is voluntary, and it was stressed to students who do not want that they do not have to fill out the survey questionnaire. Before completing the questionnaire students got the instructions, and it was thoroughly explained to them how to fill out the questionnaire. Completing the questionnaire took 20 minutes.

\section{RESULTS}

The survey was conducted on a sample of 100 respondents. When it comes to the gender structure of the sample on the basis of the presented results we can conclude that out of the total number of respondents, $61 \%$ of them were females while $39 \%$ of respondents were male.

As for the place of residence of the respondents, more than half of the respondents who participated in this study, therefore, 53\% live in urban areas. Furthermore the suburb is inhabited by $24 \%$ of respondents while in the rural areas lives $23 \%$ of respondents.

Respondents who participated in this study are primary school students and from sixth to ninth grade. Of the 100 respondents from each class we had a $25 \%$ student -respondents who participated in the study.

Below, we wanted to examine whether students respondents are punished if they get a bad grade in mathematics. Data show that the present situation is such that $64 \%$ of respondents are punished by their parents if they get a bad score. But we also have $36 \%$ of respondents who answered that in case you get a bad grade in math they pass without being penalized. In addition to questions about the punishment for the bad score, respondents were asked whether they are rewarded if they get a good grade in math. In this case, $64 \%$ of respondents stated that if they get a good grade in mathematics it is followed by prizes for this, while $36 \%$ of respondents have received no reward for a good grade.

As far as the average score at the end of the school year based on the results we see that more than half of the students, $56 \%$ of them, at the end of the school year 2015/2016 had 'very good'. In the past school year, $21 \%$ of students who participated in this study, it was'excellent', and 20\% had a 'good average'. But $3 \%$ of the previous school year ended with an average 'enough' while those with 'inadequate' were not in this study.

When it comes to the average score at the end of the school year for all respondents, we can say that the survey involved students whose average grade was in the range of 2 therefore enough, as a minimum, and 5 excellent, as the maximum rating. The average score at the end of the school year 2015/2016 for the participants of this study was $\mathrm{M}=4.0(\mathrm{SD}=.7)$. 
Much like with the average score at the end of the school year in the remainder of this paper grades in mathematics in students who participated in the study are presented. In this case, the largest number of respondents, namely $37 \%$ at the end of the year, had a 'good' grade in math, and $21 \%$ of students grade 'very good'. Furthermore, $19 \%$ of students $6-8$ class had a grade 'excellent', and $15 \%$ grade 'enough'. However, it should be indicated that in the study participated and $8 \%$ of respondents in mathematics who had had an unsatisfactory grade.

In the following interpretation of the research results we will continue to observe the grades in mathematics so that on the basis of the presented results we can conclude that the survey involved students whose score in mathematics was in a range of 1 , therefore 'insufficient' as a minimum and 5 'excellent', as the maximum score . The average score in mathematics at the end of the school year 2015/2016 for the participants of this study was $\mathrm{M}=3.3(\mathrm{SD}=1.2)$.

Before the main analysis, we checked the normality of distribution in order to determine whether the results are normally distributed, or whether it will be used parametric or nonparametric statistics.

For this purpose, we used a Kolmogorov-Smirnov and Shapiro-Wilk test for checking the normality of the distribution. First, we checked the allegations where we measured extrinsic motivation in patients. So based on the displayed results, we see that for each measured claim $\mathrm{p}<0.05$ which means that the distribution of results for claims for extrinsic measurement of motivation significantly deviate from normality.

In the second set, we examined the allegations where we measured intrinsic motivation in patients. And this case has been used Kolmogorov-Smirnov and ShapiroWilk whose results indicate that there is a statistically significant variance $(p<0.05)$ from the normality of the distribution for all measured claims. Therefore, the allegations where we measured intrinsic motivation are not normally distributed.

In the last set of allegations we measured how distributed allegations relate to the praise and punishment in children. And also for this set of statements the results of Kolmogorov-Smirnov and Shapiro-Wilk test show that for each measured claim $p<0.05$, which means that the distribution of the results for all the claims, statistically significantly deviates from the normal distribution.

On the basis of all the displayed results, we see that all the claims from the questionnaire have a distribution of results, which significantly deviate from normality, which is why below is usednonparametric statistic to check statistical importance.

Claims in the survey are divided into 3 sets which we measured: extrinsic motivation, intrinsic motivation, and praise and punishment for the students.

Extrinsic motivation was measured by the 9 claims, and on this scale the maximum score was 45 , and the minimum 9, with the lowest score that any of the students had was 26. Average value for extrinsic motivation was $\mathrm{M}=36.9(\mathrm{SD}=4.2)$.

When it comes to intrinsic motivation, it was measured through 6 claims in the questionnaire, and consequently the highest possible score was 30 , with the highest in our survey result obtained was 27 , and the lowest 8 . Average value on a scale of intrinsic motivation was $\mathrm{M}=14,9(\mathrm{SD}=3,8)$. We ended up the questionnaire with 4 claims where we measured the impact of praise and punishment to motivate students measured by the 4 claims where the maximum possible score on the scale was 20 , and the minimum 4 . Average value of claims where we measured the impact of praise and punishment was $\mathrm{M}=13.6(\mathrm{SD}=2.4)$.

In the remainder of this paper we analyzed the individual claims where we examined extrinsic motivation. The students could score each statement considering the extent to which they agree with a statement with scores of 1 , which means that it does not agree, to 5 , which means that it fully agrees with that statement. It is interesting to note that the respondents showed the highest level of agreement with the statement that follows: The most important are grades in math, but not the knowledge, where it was $\mathrm{M}=4.4(\mathrm{SD}=0.8)$. Based on this, we see how students value more grades, rather than acquired knowledge that will be useful in life and in further education. On the other hand claim with which students the least agree:I like when the teacher reads aloud marks because everyone can hear that I got a good grade, where the average score was $\mathrm{M}=3.3$ $(\mathrm{SD}=1.5)$.

The next in the line as the object of analysis were the claims that are used for the examination of intrinsic motivation. The students could also in this case rate every claim considering the extent to which they agree with it, with scores of 1 , which means that it does not agree, to 5 , which means that you fully agree with this statement. Looking at the results shown in the table, we can conclude that the students who were the participants of this research to a lesser extent, agree with the statements which shows a relatively low average grades. 
Namely, the highest level of agreement was reached with this claim: I prefer to study and to earn a grade in mathematics, than to have it as a gift, from which we see that the students still want to get the well-deserved grade proportional to the effort they have invested, and not to have higher grades given to them as a present $\mathrm{M}$ $=2.9(\mathrm{SD}=1.2)$. However at the claim:I'm ashamed if my teacher gifts me grade in mathematics that I didn't deserve, we got the lowest average score that is $\mathrm{M}=$ $2.1(\mathrm{SD}=1.1)$.

When it comes to the claims relating to the praise, or criticism, we can say that students and in this case also used ratings from 1 to 5 to appraise the level of agreement with each of the claims and the highest degree of consent and, therefore, the highest average rating was observed in the claim:I'm trying to get good grades in Math, so my parents would not criticise or punish me $\mathrm{M}=3.7(\mathrm{SD}=1.3)$. On this basis, we can conclude that students want to satisfy the expectations of their parents in order not to be criticised for the poor success in school. The lowest ratings and, therefore, the smallest level of consent we received at the claim:I'm studying to get good grades in Math just because my parents will reward me, where $\mathrm{M}=3.2(\mathrm{SD}=1.2)$ and at the claim: When my teacher criticises me because of the poor grade, I'm trying to learn it as soon as possible and fix the grade, at which the average rating was $\mathrm{M}=$ $3.2(\mathrm{SD}=1.0)$.

In the remainder of this paper, we investigated whether there are statistically significant differences in extrinsic motivation between boys and girls. The maximum number of claims which were measuring extrinsic motivation was 50 . The men achieved an average result of $\mathrm{M}=36.0(\mathrm{SD}=4.4)$ while for females the average score was $\mathrm{M}=37.5(\mathrm{SD}=4.0)$.

We were interested in whether there are statistically significant differences in the impact of extrinsic motivation on academic achievement due to gender. The results show that there is no statistically significant difference in extrinsic motivation between boys and girls. Furthermore, the aim was to test a statistically significant difference in intrinsic motivation between males and females. The maximum sum of the claims which measured intrinsic motivation was 30 , men have achieved an average score $\mathrm{M}=14.3(\mathrm{SD}=4.4)$, while for females the average score was $\mathrm{M}=15.3(\mathrm{SD}=3.8)$. The results of the Mann-Whitney $U$ test confirmed that there was no statistically significant difference in the elements that make intrinsic motivation regardless of whether it is a male or female respondents.
In continuation of the subject of the analysis was the comparison of elements that relate to praise or punishment of students. The maximum sum of the claims which measured praise and punishment was 20. Based on these results we see that the average score that relates to praise or punishment in male and female subjects is identical and it is $\mathrm{M}=13.6(\mathrm{SD}=3.0)$ and at students it is $\mathrm{M}=13.6(\mathrm{SD}=2.1)$. Object of interest for us wass whether there are significant differences in the application of praise or punishment in male and female subjects. The results show that there is no statistically significant difference in the application of praise and punishment regardless of gender.

In the remainder of this paper, we investigated the effect of extrinsic motivation, depending on which grade of primary school attended respondent. So the biggest impact of extrinsic motivation was reported by respondents who attended seventh grade where the average score was $\mathrm{M}=37.7$ ( $\mathrm{SD}=3.4)$, while the other lower grades distributed in around a narrow range.

We wanted to examine whether there are significant differences in the impact of the elements of extrinsic motivation in relation to the grade which attends the respondent. In relation to this, the Kruskal Wallis test as non-parametric measure of statistical significance between multiple groups (more than 2 groups). Based on the data we see that $p>0.05$ there is no statistically significant difference in the impact of certain elements of extrinsic motivation among respondents with respect to which grade of primary school they attend.

When it comes to intrinsic motivation and impact of its elements to the success of students, the highest average grade recorded the eighth grade students where $\mathrm{M}=$ $16.4(\mathrm{SD}=4.3)$, while in ninth grade students factors that make intrinsic motivation have the least impact as seen from the lowest average scores that were achieved with $\mathrm{M}=13.6(\mathrm{SD}=3.2)$.

Based on the results of Kurskal Wallis test we see that there is no statistically significant difference when it comes to the influence of intrinsic motivation to students unrelated to the grade students attend.

The data shown in the table relating to the praise and punishment shows that the greatest impact of these elements achieved in subjects who attended sixth grade where $\mathrm{M}=14.0(\mathrm{SD}=2.5)$, while the other lower grades were distributed in approximately narrow range. Based on these results we can conclude that there is no statistically significant difference in the values of ratings related to the praise and punishments regardless of the grade of primary school which attends the respondent. 
In continuation the subject of the analysis was the influence of certain elements of extrinsic motivation on academic achievement of students with regard to their place of residence. In this regard, the greatest impact of extrinsic motivation is present in students who live in the suburbs where the average score was $\mathrm{M}=37.4$ (SD $=4.9$ ) and with students who live in rural areas where $\mathrm{M}=37,4(\mathrm{SD}=4.3)$. However with students who live in urban settlement we received a slightly lower average grade $\mathrm{M}=36.5$ ( $\mathrm{SD}=3.9$ ), which indicates a smaller influence of extrinsic motivation.

The results from the application of Kurskal Wallis test show that in this matter also there is no statistically significant difference in the impact of the individual elements of extrinsic motivation on students considering which type of area students live.

Similar to the previous analysis, in this case we also examined how the elements of intrinsic motivation affect the students with regard to whether they live in urban, suburban or rural type of settlement. As we can see in the table the elements of intrinsic motivation largely affect the success of students who live in a rural area, what can be seen from the highest average ratings by these students achieved $\mathrm{M}=16.4(\mathrm{SD}=3.6)$.

Based on these results we conclude that $p>0.05$, which means that there is no statistically significant difference in assessment of intrinsic motivation regardless of the place of residence of the respondents.

When it comes to the application of praise and punishment and its impact on students' academic achievement, we can conclude that students from suburban areas recorded highest average ratings $\mathrm{M}=13.7$ (SD $=2.3$ ), based on which we can conclude that elements of praise or punishment most affect the success of students in this type of settlement.

Based on these results we see that there is no statistically significant difference between respondents in each region in terms of the degree of influence of the praise or punishment to success in school.

When it comes to the influence of extrinsic motivation factors on work of students on the basis of the obtained results we can conclude that these factors most affect students who at the end of the school year achieved great success. Therefore, at the 'excellent' grade students was the highest average rating $\mathrm{M}=40.1$ ( $\mathrm{SD}=$ 3.7) which is of course understandable that students with the best school achievement have the largest motivation for success. However, the smallest impact of extrinsic motivation was recorded in students with 'sufficient' success that can be seen from the least average grade which refers to the impact of these factors in the amount of $\mathrm{M}=30.3(\mathrm{SD}=2.5)$.
Using the Kruskal Wallis test, we got the results that show that there is a statistically significant difference at the impact of extrinsic motivation factors where the biggest impact has been achieved in students who had 'excellent' grade success at the end of the school year. Below the objects of analysis were intrinsic factors analysis and its impact on school success of students. In relation to this, the results show that with these factors, the biggest impact has been achieved in students with 'excellent' grade success where $\mathrm{M}=19.3$ ( $\mathrm{SD}=$ 3.7) and the smallest in students with 'sufficient' success in which the average rating is $\mathrm{M}=10.7(\mathrm{SD}=2.1)$. In this case we were using the Kruskal Wallis test as well to check whether there is a statistically significant difference in the impact of the elements of intrinsic motivation on the school success of students.

According to the results, which are shown in the table we see that the $p<0.05$, which means that there are statistically significant differences in the impact of intrinsic motivation on the school success of students where the greatest impact has been achieved in students with 'excellent' grade success.

Below we examined are students according to the school success statistically significantly different when it comes to the impact of the praise, or punishment. On the basis of displayed mathematical middle ground we see that they are in students with 'excellent' grade success with praise or penalties achieved the best results of $\mathrm{M}=14.9(\mathrm{SD}=2.3)$ and in students whose school success was 'enough' achieved the worst results of $\mathrm{M}$ $=10.0(\mathrm{SD}=2.0)$.

Results displayed in the table show that there is a statistically significant difference in the level of influence of the praise, or punishment on the results that students achieve whereby these factors most impact show in students with 'excellent' grade success. As the next topic we questioned the existence of statistically significant difference when it comes to the influence of extrinsic motivation factors on the matter of the final grade from the subject of mathematics that student will achieve. Thus we see that 'excellent' gradestudents achieved significantly higher scores on this issue with an average value of $\mathrm{M}=40,6(\mathrm{SD}=2.4)$ with regard to students with 'sufficient' final grade in Math whose average value amounted to $34.8 \mathrm{M}=(\mathrm{SD}=5.4)$.

The results of the Mann-Whitney U test confirm that the aforementioned differences are statistically significant $(\mathrm{p}<0.05)$, which means that in students with an 'excellent' grade from the mathematics in a statistically significantly greater extent present impact of extrinsic motivation in relation to the students with lower grades in this subject. 
In addition, we examined whether there are statistically significant differences in the degree in which the elements of intrinsic motivation have an impact on the final grade in mathematics that students achieve, where again we see that students with an 'excellent' grade have presented the greatest influence of intrinsic motivation in relation to other students $\mathrm{M}=16.1$ (SD $=3.7$ ).

However, the difference in the arithmetic environments are not large enough to be statistically significant and this is shown by the results of Kruskal Wallis test where we see that $p>0.05$, which means that there is no statistically significant difference between subjects with different grades in mathematics in terms of the influence factors of intrinsic motivation.

Furthermore, we investigated whether there are statistically significant differences in the attitude of respondents about how much praise or punishment has an impact on the students according to which final grade is there in Math, where again we see that respondents with 'excellent' grade show the presence of the influence of the praise or punishment to the fullest extent $\mathrm{M}=14.0$ ( $\mathrm{SD}=1.6)$, unlike students with 'insufficient'grade for which the results show that these measures are having an effect at least $\mathrm{M}=12.6$ $(\mathrm{SD}=3.5)$. However, this time too, the results show that these differences cannot be regarded as statistically significant because $p>0.05$, which means that praise and punishment are not a factor that affects the final grade in Math.

As the next topic we questioned the existence of statistically significant differences when it comes to the influence of extrinsicmotivation on students with regard to whether they are punished or not if they get a worse grade. Thus we see that in students who are punished, there was recorded a slightly higher impact of extrinsic motivation factors with an average value of $\mathrm{M}=37.1(\mathrm{SD}=3.8)$ compared to students who are not punished $\mathrm{M}=36.5(\mathrm{SD}=4.9)$.

However, the results of the Mann-Whitney U test, with which we questioned whether statistically significant differences are mentioned show that $p>0.05$, which means that there is no statistically significant difference between the students who have been punished and those who are not, when it comes to extrinsic motivation.

In the continuation, we examined whether there are statistically significant differences in the level of influence of intrinsic motivation among the respondents with regard to whether they would be punished or not in the event that in school they get a worse grade. Thus we see that less arithmetic average achieve learners who are punished for bad grades $\mathrm{M}=14.9(\mathrm{SD}=3.5)$, while the larger arithmetic achieve respondents who did not receive a punishment for a lower grade of $\mathrm{M}=$ $15: 1(\mathrm{SD}=4.4)$.

However, the differences in the environments of the arithmetic are not large enough to be statistically significant and this is shown by the results of the MannWhitney U test, where we see that $p>0.05$, which means that there is no statistically significant difference between the respondents in terms of the level of intrinsic motivation whether they are punished or not for a worse grade.

In addition, we examined whether there are statistically significant differences in the attitude of respondents about how much praise or punishment have an impact on the students according to whether the student is being punished if he gets a worse grade. The results show that we have the same arithmetic average in both cases, which means that with students who are punished, but also with those who pass without punishment there is the same effect on the praise or punishment.

On the basis of the displayed results, we see that there are no statistically significant differences in the level of impact of praise or punishment between students with regard to whether or not they are punished for bad grades and actually both achieve the same or statisticallyinsignificant different results on a scale with which we measured the level of impact of the praise or punishment on students' success.

In the end, we checked whether there are statistically significant differences in the level of extrinsic motivation between the students who have been awarded for good grades and those that are not. On the basis of the view of arithmetic average we see that in average values students do not differ when considering rewards. Thus we see that in students who are rewarded, there was recorded a lesser influence of extrinsic motivation factors with an average value of $\mathrm{M}=36.9(\mathrm{SD}=4.3)$ compared to students who were not awarded $\mathrm{M}=37.0$ $(\mathrm{SD}=4.2)$.

However the results of the Mann-Whitney U test, with which we examined whether they are the statistically significant differences, show that the $p>0.05$ which means that there is no statistically significant difference between the students who have been awarded and those that are not, when it comes to extrinsic motivation.

In addition, we examined whether there are statistically significant differences in the level of an influence on intrinsic motivations between the respondents given that they would be rewarded or not in the event that they receive a good grade in school. 
Thus we see that less arithmetic average achieve students who are rewarded for good grades $14.7 \mathrm{M}=(\mathrm{SD}$ $=3.7$ ), while the higher arithmetic average achieve respondents who did not receive a reward for a good grade $=15,4 \mathrm{M}(\mathrm{SD}=4: 1)$.

The difference in arithmetic environments are not statistically significant, this is shown by the result of the Mann-Whitney U test, where we see that $p>0.05$, which means that there are no statistically significant differences in the degree of the influence of intrinsic motivation, when rewarding students for a good grade is considered.

We further examined to see if there are statistically significant differences in the attitude of the students about how much praise or punishment have an impact on them according to whether they are rewarded for a good grade. On the basis of displayed mathematical backgrounds we see that praise, or the punishment have approximately the same effect even with the students who receive a reward $(\mathrm{M}=13.5 \mathrm{SD}=2.2)$ and students who are not rewarded for a good grade $(\mathrm{M}=$ 13.8 SD = 2.8).

According to shown approximate arithmetic environments between rewarded students and those who do not receive the prize, and the results of the MannWhitney $U$ test show that there is no statistically significant difference in the level of the impact of the praise or punishment.

Finally, we examined the existence of correlation between the measured variables, or the existence of a correlation between extrinsic, intrinsic motivation, and reward and punishment. To test the correlation Spearman's correlation coefficient was used, since the distribution of the results is not normal which means thatnonparametric statistics was used. Thus we see the basis of the presented results a statistically significant correlation between extrinsic and intrinsic motivation does exist (0.537), which is to be expected that students who are more intrinsically motivated are also extrinsically more motivated. Furthermore statistically significant correlation between extrinsic motivation and praise and punishment was found $(0,256)$, which means that students who are more extrinsically motivated greater effect of reward and punishment has on them. Similar results were obtained for intrinsic motivation, where a statistically significant correlation between intrinsic motivation and reward and punishment was found $(0,326)$, which means that students who are more intrinsically motivated are also more influenced by reward and punishment.

\section{DISCUSSION}

Results of this study showed us that students in elementary schools have more developed extrinsic motivation than intrinsic motivation when it comes to mathematics. The respondents through answers to the questionnaire survey showed that knowledge of mathematics is not perceived as something that will be useful in everyday life, but are mainly focused on getting good grades in mathematics for grade point average, to facilitate enrollment in high school, or for praise by teachers or parents. These results are consistent with other studies in which it was confirmed that primary school students are aware of mathematics' role in their education and life, but despite this they learn mathematics mainly because of the grade which is their chief and strongest motivator for learning math (Benčeki Marenić, 2006).

Certainly parents play an important role in the development of these attitudes in children, where the results showed that $64 \%$ of parents reward their children for good grades and an equal number of parents punish their children when they get a bad grades. Reward and punishment certainly contribute to children developing more extrinsic motivation toward mathematics. If you take into account that many areas of mathematics and many assignments that children face in this case are quite abstract, it is clear that students can not perceive the importance of mathematics in everyday life. In this paper we wanted to examine and determine the socio-demographic factors that affect the motivation of students to learn mathematics and how the math grades affect the motivation of the students. The results showed that the sex of the students does not play a role in the motivation of students. Boys and girls in equal measure are motivated to learn math, and equal factors make them motivated. When it comes to the age of the respondents, older students have more pronounced extrinsic motivation andperceivegrade in math as important factor that motivates them. These results are expected if we take into account that older students think more about enrolment in high school, and their grades and grade point average are primary motivators in this period of life. Furthermore, we received the results which have confirmed that the children from suburban and rural villages are more intrinsically motivated compared to children from the urban areas. 
If we take into account that parents of children who live in rural settlements, are probably weaker financially and economic in relation to the parents of children who live in urban settlements, we come to the conclusionthat rewarding children in urban settlements leads to these children having more expressed their extrinsic motivation which becomes primary, and has as a consequence that the intrinsic motivation is less expressed. In this paper we also observed how GPA affects its students ' motivation. The results showed that students with a higher average rating have greater motivation, intrinsic as well as extrinsic. Students who have a lower average rating have lower motivation,intrinsic and extrinsic. Thus, these results show clearly how much is motivation important for learning in children. However, if we look at students based on their rating of their final grade in math, and not only on the basis of the overall average rating, we see that excellent students have significantly more developed extrinsic motivation in relation to intrinsic. These results clearly indicate the importance of the grades in math and their impact on the motivation of students. So the students with better grades in mathematics are more motivated by those grades or for these students grade represents the main motivator who pushes them to study mathematics. On the other hand, we have students who have bad grades in math, and to such students grades cannot act as the motivator. Probably with these students occurs learned helplessness as a consequence of the bad grade in mathematics, because here we are talking about the bad final grades that are long-standing and not on temporary bad grades, as a consequence of bad test or the oral examination of the student. Learned helplessness is one form of acquired conditionality, and refers to the phenomenon that people or animals shall not take action to eliminate the negative or painful situation, if they start to believe that there is no causeand-effect relationship between their conduct and the outcome of the situation (Zarevski, 1997). Often is cited the example of a math teacher who consistently from day to daygives negative grades, and createsin students learned helplessness. In fact it proved that a failure on cognitive tasks can lead to learned helplessness (Zarevski, 1997). So the teacher withgrades can motivate students who have good grades and to whom grade point average is important, while in students with poor grades and GPA, individual score in mathematics cannot start the motivational processes that will have long-term effects in students.
Finally, we wanted to examine how parents' behaviour in terms of punishment or reward of students affects the motivation of students in mathematics. As previously indicated $64 \%$ of parents punish their children for bad grades, and rewards them for good grades. However the results of this study show that punishment and reward do not play a role when it comes to intrinsic and extrinsic motivation of students. The results of this research have shown that there are no statistically significant differences in the level of intrinsic and extrinsic motivation of students whose parents reward and punish them and students whose parents are not punishing and not rewarding them for their grades. These results can be explained by the fact that parents reward and punishment are not enforced consistently and methodologically, but they are predictable in their behaviour which has resulted in that the students expect reward or punishment, and as such have no form of motivators that will lead to significant changes in the behaviour of students.

\section{CONCLUSION}

The results of the research show that there are no gender differences in the perception of the marks in mathematics as the motivator in learning. So, the boys and girls in equal measures perceive evaluation in mathematics as the motivator for learning.

Due to the age of the students there are statistically significant differences in the perception of the marks in mathematics as the motivator for learning. At the eighth-grade students the most expressed is the intrinsic motivation for learning, while it is the least expressed in students of the seventh and the ninth grade. When it comes to the extrinsic factors of motivation any statistically significant difference was not obtained based on age of the respondents.

Survey confirms that the children from the rural settlements have a higher intrinsic motivation compared to children from urban settlements. When it comes to the extrinsic motivation, rewarding or punishing students did not provide any statistically significant differences between students who live in urban and rural areas.

The research results have shown that the level of extrinsic motivation is growing with an average rating of grades, i.e., that the greatest extrinsic motivation have great students, and the minimum sufficient. 
The same results are obtained in the terms of intrinsic motivation as well as in terms of the impact of the reward and punishment as a factor for motivation of students.

When it comes to categorization of students by the final grade in Math, the results of the research show that the highest level of extrinsic motivation have 'great' grade students, and the minimum 'sufficient' grade students. In terms of intrinsic motivation as well as the impact of reward and punishment, any statistically significant differences were not obtained between the students involved who were divided in groups based on the final grade in Math.

No matter whether parents punish children for bad grades in Math or not, this factor does not lead to a change in the level of intrinsic or extrinsic incentives, so that the punishment of parents does not affect the motivation of children in statistically significant measures.

Rewarding students by parents is not a factor that leads to statistically significant differences at the lev- el of the intrinsic or extrinsic motivation in students. This was shown by the results of this study, where it is not obtained statistically significant difference in the level of intrinsic and extrinsic motivation due to the categorization of the pupils on the basis of whether their parents reward them for good grades or not.

\section{REFERENCES}

Benček, A., \& Marenić, M. (2006). Metodički obzori: Časopis za odgojno-obrazovnu teoriju i praksu, 1.

Dhority, L. (1992). Ustvarjalne metode učenja. Ljubljana: Alpha Center.

Ginnis, P, (2002). Učitelj - sam svoj mojster. Kakov sakega učenca pripeljemo do uspeha. Ljubljana: Rokus.

Požarnik, B. (2000). Psihologijaučenja in pouka. Ljubljana: DZS.

Rakić, B. (1977). Motivacija i školsko učenje. Sarajevo: Veselin Masleša.

Rešić, S. (2003). Matematika i metodika početne nastave

Woolfolk, A. (2002). Pedagoška psihologija. Ljubljana: EDUCY.

Zarevski, P. (1997). Psihologija učenja i pamćenja. Naklada slap. 